
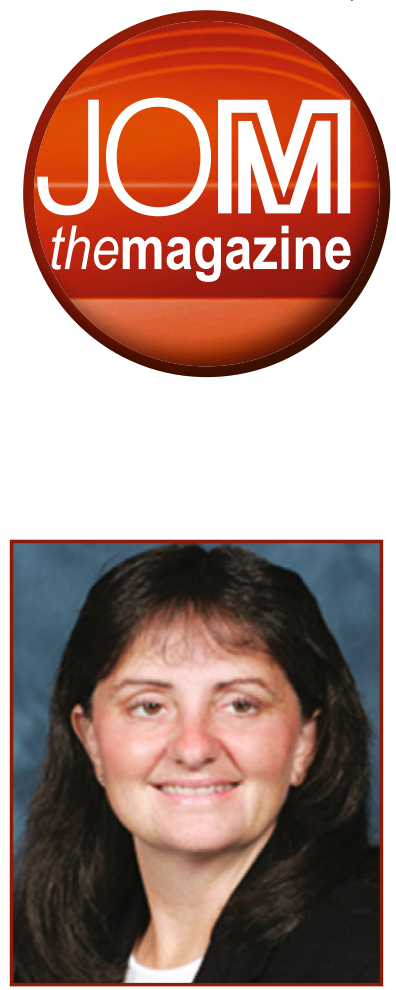

Tresa Pollock

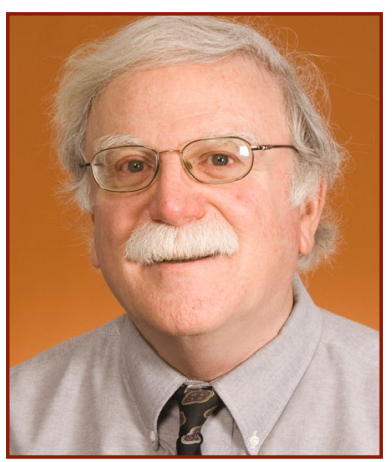

David Laughlin

\title{
Metallurgical and Materials Transactions Announces Incoming Principal Editor; JOM Best Paper Awards
}

\section{new and noteworthy at TMS}

Turn to this regular JOM feature for information on new TMS initiatives, updates, and overviews of TMS events and activities, as well as news from the field that impacts TMS and its members. To submit news items for consideration, contact Lynne Robinson, JOM Contributing Editor, at Irobinson@tms.org.

\section{Tresa Pollock Named Incoming Principal Editor for Metallurgical and Materials Transactions}

The new principal editor of the Metallurgical and Materials Transactions (Met.Trans.) family of journals will be Tresa M. Pollock, an internationally recognized leader in the science and technology of advanced structural alloys with applications in the aerospace, energy and automotive industries. The Alcoa Professor and chair, Department of Materials, University of California, Santa Barbara (UCSB), Pollock will begin her editorship on September 1, 2016, working alongside current principal editor, David Laughlin, through the end of 2016 when he steps down from the position. Laughlin, the Alcoa Professor of Physical Metallurgy at Carnegie Mellon University, has led Met.Trans. as principal editor since 1987. Pollock likewise has a long association with Met.Trans., having served as an associate editor since 1997.

Jointly published by TMS and ASM International, Metallurgical and Materials Transactions was founded as the Metallurgical Transactions journal in 1970, and has since expanded to encompass three highly respected, peerreviewed archival journals for metallurgy and materials science. Met.Trans. $A$ is a monthly publication focused on physical metallurgy and materials science. Met. Trans. $B$ publishes contributions bimonthly on the theoretical and engineering aspects of the processing of metals and other materials. Launched in 2014, Met.Trans. E is a quarterly journal exploring the science of materials being investigated or applied to address unique aspects of current and emerging energy technologies.

James J. Robinson, TMS Executive Director, commented that Pollock's appointment as the new principal editor has "clearly poised Met. Trans. to go from one Golden Age to another." Robinson also praised Laughlin's long-time leadership, saying, "Within our science and engineering community, Metallurgical and Materials Transactions has stood, literally for decades, as a pinnacle publishing destination for our field. This is in no small part attributable to the clear and consistent leadership and editorial vision of David Laughlin and the vast team of contributors that he has assembled. The importance of the effort that he has put toward Met. Trans. cannot be overestimated."

"It is exciting and gratifying that another long-time member of David's editorial team-Tresa Pollock-will succeed him as editor in chief," Robinson continued. "There is no doubt that $A, B$, and $E$ under Tresa will not just retain, but grow their reputations as capstone publishing destinations."

Pollock launched her professional career at GE Aircraft Engines, where she developed advanced superalloys for gas turbine engines. In 1991, she joined the materials science and engineering faculty at Carnegie Mellon University, later moving to the University of Michigan in 2000, where she held the L.H. and F.E. Van Vlack Professorship of Materials Science and Engineering. She joined the Materials Department at UCSB in 2010. Pollock's current interests span the mechanical and environmental performance of materials 
in extreme environments, unique high temperature materials processing paths, ultrafast laser-material interactions, alloy design, and 3-D materials characterization. She received her bachelor's degree from Purdue University and holds a Ph.D. from the Massachusetts Institute of Technology.

Within her realms of expertise, Pollock has organized numerous international meetings and symposia, authored more than 260 publications, and holds three patents. She is widely regarded as a thought leader on issues of critical importance to the field and has contributed to an array of national initiatives on these topics. Most notably, Pollock was chair of the committee that produced the ground-breaking study, Integrated Computational Materials Engineering (ICME): A Transformational Discipline for Improved Competitiveness and National Security, released by the National Research Council of the National Academies in 2008. This study would serve to identify the tremendous potential of ICME in accelerating materials and manufacturing innovation.

Pollock's numerous awards and honors include election to the National Academy of Engineering in 2005 and induction as a TMS Fellow in 2009 "for seminal contributions in the understanding of high temperature alloys, and for distinguished leadership in materials education and the materials profession." She is also the 2005 TMS president - the first female to hold that office. Her extensive volunteer leadership with TMS includes a term on the Board of Directors as Director/Chair of the Structural Materials Division.

For additional information on the Metallurgical and Materials Transactions family of publications, visit www.tms.org /pubs/journals/MT/MT.aspx. TMS members have free electronic access to these and other TMS published journals, including decades of archived articles.

\section{JOM Announces the 2016 Best Paper Awards}

The TMS Light Metals Division (LMD) and Structural Materials Division (SMD) both presented 2016 JOM Best Paper Awards during their division luncheons at the TMS 2016 Annual Meeting \& Exhibition in February.

"PFC Emissions from Detected Versus Nondetected Anode Effects in the Aluminum Industry," by David S. Wong, Paul Fraser, Pascal Lavoie, and Jooil Kim is the 2016 LMD JOM Best Paper. Published in the February 2015 issue, this article focused on reviewing the discrepancy between the levels of perfluorinated carbon compounds (PFCs) generated in aluminum reduction cells during anode effects (AEs) reported by the aluminum industry and atmospheric measurements of global PFC emissions. In their paper, Wong et al. discuss the recent presence of unaccounted PFCs generated outside of the conventional AE definition. The authors then propose two additional AE categories: low-voltage, propagating AEs and nonpropagating AEs.

G.R. Odette's December 2014 article "Recent Progress in Developing and Qualifying Nanostructured Ferritic Alloys for Advanced Fission and Fusion Applications" is the 2016 SMD JOM Best Paper. Odette reviews progress on developing nanostructructed ferritic alloys, focusing mainly on Fe-Cr-based ferritic steels with a high concentration of Y-Ti-O nano-oxide features. These structural materials are capable of managing very high helium concentrations, have outstanding hightemperature properties, and possess unique irradiation tolerance and thermal stability. In his review, Odette provides background and progress on the character of the nanofeatures, insights on mechanical properties, a quantitative model of nanofeature coarsening, recent irradiation experiments, and a new mechanism that controls the transportation, fate, and consequences of helium.

Award recipients are determined by the each council's award committee and JOM advisors. The JOM best paper awards recognize the author(s) of a paper published in an issue of the preceding year's volume of JOM under a light metals-related or structural materials-related technical topic.

TMS members have free access to these papers, as well as the full JOM archive dating back to 1970. Log on to jom.tms .org and select the JOM: Issue Archive. Navigate to Volume 67, Issue 2 for the LMD Best Paper, and Volume 66, Issue 12 for the SMD Best Paper.
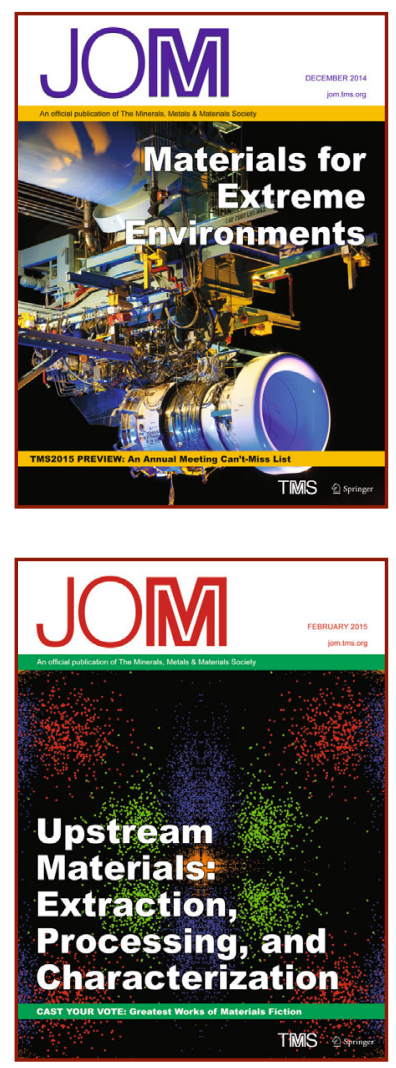